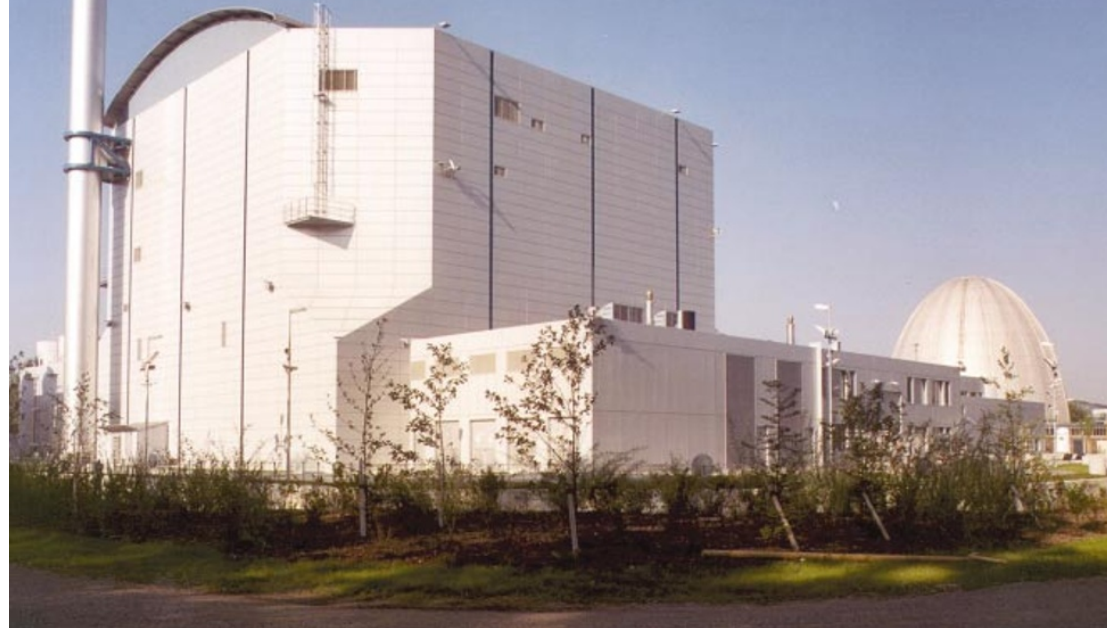

Fuelling controversy: the FRM-II research reactor is likely to use highly enriched uranium until 2010.

\title{
Neutron source powers ahead with weapons-grade uranium
}

Quirin Schiermeier, Munich

The German government has given the go-ahead for the operation of a research reactor that will be fuelled by highly enriched uranium (HEU).

The decision, announced on 15 April, ends years of argument over whether scientists should be allowed to use a reactor whose fuel could be readily diverted to make nuclear weapons. But the government is demanding that by 2010 the FRM-II research reactor at Garching, near Munich, should be converted to use low-enriched uranium.

Despite continuing opposition from non-proliferation experts and nuclear watchdog groups, the US\$400-million facility is now likely to become fully operational this year. The facility was ready in 2001, but has been mothballed pending the decision.

The FRM-II is the world's first large research reactor to open in the past 25 years that burns HEU, a weapons-grade material containing more than $90 \%$ of the isotope uranium-235 (see Nature 414, 5; 2001).

The 20-megawatt facility will give physicists, chemists, biologists and engineers access to an intense flux of neutrons for investigating materials and molecules. It incorporates 14 beam lines and 5 other radiation facilities for such experiments, including a unique source of 'ultracold' neutrons and a powerful positron probe. Ultracold neutrons move very slowly and are useful both for the study of neutrons themselves and for other applications, such as optics. The positron probe will be used to investigate atomicscale structure and defects in solids.

"We'll finally be able to show what fantastic opportunities neutrons have to offer, and we can begin to train the next generation of neutron researchers," says Winfried Petry, scientific director of the FRM-II.

But not everyone in the neutron community is as thrilled as Petry. Some contend that the risks surrounding the use of HEU are too high a price to pay for the expected scientific gain.

"Basically, this is the technology of the 1960s. There is absolutely no scientific requirement any longer for using HEU in a research reactor," says Franz Fujara, a physicist at the Technical University of Darmstadt who has been involved in neutron research for more than 25 years. Fujara says he will not apply to use the FRM-II as long as it is run on weaponsgrade fuel.

Converting the reactor to use lowenriched uranium fuel will reduce its neutron flow density, according to a technical advisory committee to the government, but will not significantly limit its scientific usefulness (see Nature 400, 7; 1999).

But the German government has not yet specified just how low the uranium enrichment must be after the conversion. Under international agreements, only uranium containing less than 20\% uranium-235 is considered non-weaponsgrade, low-enriched uranium (LEU).

"We are working together with industry on the development of a new high-density LEU fuel," says Petry. "But there is no guarantee that a fuel element that suits the FRM-II's design will be available by 2010."

www.frm2.tu-muenchen.de/index_en.html
Human fatality adds fresh impetus to fight against bird flu

Alison Abbott, Munich

The death on 17 April of a veterinarian who contracted flu from chickens in the Netherlands has heightened concerns about the threat posed by the disease.

Since the outbreak of the illness in late February (see Nature 422, 247; 2003), 18 million chickens have been culled in the Netherlands - including six million killed last week close to the German border. But the flu has now spread to birds in Belgium, prompting the slaughter there of hundreds of thousands of chickens.

Transmission of the disease to humans remains a major concern. Ron Fouchier, a virologist at Erasmus University in Rotterdam who monitors human cases of the avian virus, says that he "remains very worried" about the outbreak.

Since 28 February, 83 people have become infected with the virus, known as H7N7. Most have suffered only conjunctivitis, but eight have developed mild flu-like symptoms. The vet, who was from Den Bosch, died from pneumonia.

"The numbers are, of course, small but the death rate among those with flu-like symptoms is similar to that for the Hong Kong outbreak in 1997," says Fouchier. In Hong Kong, 18 people suffered flu-like symptoms and six died from a bird-flu virus identified as H5N1.

Neither H7N7 nor H5N1 spreads rapidly between humans, so a pandemic is thought to be unlikely. "But we don't have things under control," Fouchier says.

The number of new cases in humans has slowed in the Netherlands since 10 March, when at-risk workers began taking the antiviral drug Tamiflu. Belgium has also introduced measures to protect people working with chickens.

Marion Koopmans, a spokeswoman for the RIVM, the Netherlands' publichealth laboratory, warns that other countries should be on alert, particularly as the chicken cull involved several thousand foreign labourers.

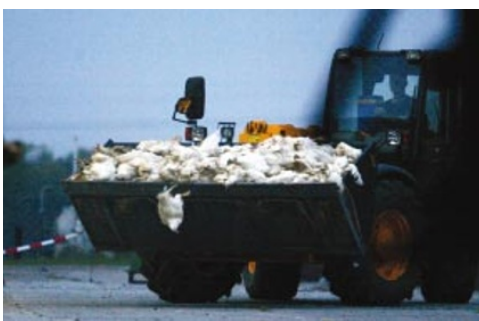

Disease burden: 18 million Dutch chickens have been culled in the fight against bird flu. 